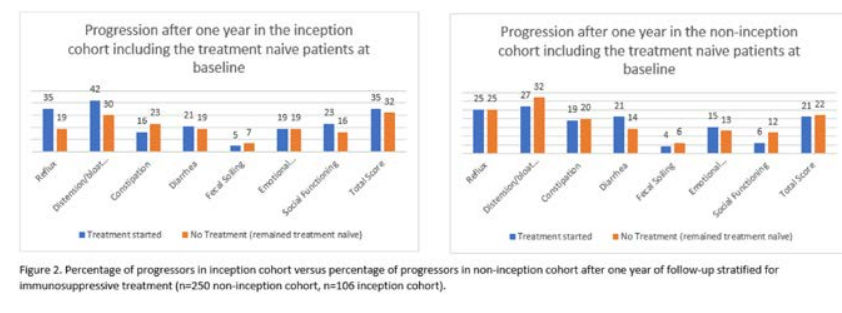

Acknowledgments: NA

Disclosure of Interests: Nina van Leeuwen: None declared, Håvard Fretheim: None declared, Øyvind Molberg: None declared, Thomas Huizinga Grant/ research support from: Ablynx, Bristol-Myers Squibb, Roche, Sanofi, Consultant of: Ablynx, Bristol-Myers Squibb, Roche, Sanofi, Jeska de Vries-Bouwstra: None declared, Anna-Maria Hoffmann-Vold Grant/research support from: Boehringer Ingelheim, Consultant of: Boehringer Ingelheim, Actelion, Bayer, GlaxoSmithKline, Speakers bureau: Boehringer Ingelheim, Actelion, Roche

DOI: 10.1136/annrheumdis-2020-eular.642

\section{THU0328 SAFETY AND EFFICACY OF SUBCUTANEOUS TOCILIZUMAB IN SYSTEMIC SCLEROSIS: RESULTS FROM THE OPEN-LABEL PERIOD OF THE PHASE 3 FOCUSSCED TRIAL}

D. Khanna ${ }^{1}$, C. J. F. Lin ${ }^{2}$, H. Spotswood ${ }^{3}$, J. Siegel ${ }^{2}$, D. Furst ${ }^{4}$, C. Denton ${ }^{5}$. ${ }^{1}$ University of Michigan, Ann Arbor, United States of America; ${ }^{2}$ Genentech, South San Francisco, United States of America; ${ }^{3}$ Roche Products Ltd, Welwyn Garden City, United Kingdom; ${ }^{4}$ University of California, Los Angeles, Los Angeles, United States of America; ${ }^{5}$ University College London, London, United Kingdom

Background: The anti-interleukin-6 (IL-6) receptor-a antibody tocilizumab (TCZ) demonstrated skin score improvement and forced vital capacity (FVC) preservation in patients with systemic sclerosis (SSc) in a phase 2 randomized controlled trial. ${ }^{1,2}$ Data from the 48-week, double-blind (DB), placebo (PBO)-controlled period of the focuSSced phase 3 trial were previously presented, ${ }^{3}$ and open-label $(\mathrm{OL})$ data up to week 96 are presented herein.

Objectives: To assess the long-term safety and efficacy of TCZ in SSC patients.

Methods: Adult patients with active SSc ( $\leq 60$-month duration, modified Rodnan skin score [mRSS] 10-35, and elevated acute-phase reactants) treated with PBO or TCZ in the DB period received OL TCZ $162 \mathrm{mg} \mathrm{SC}$ weekly from weeks 48 to 96

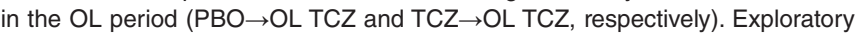
analysis of data up to week 96 included no formal statistical analyses. Changes in mRSS and percent predicted FVC (ppFVC) were assessed.

Results: Overall, 92/105 TCZ (88\%) and 89/107 PBO (83\%) patients entered the OL TCZ treatment period at week 48, and 85/105 TCZ $\rightarrow$ OL TCZ (81\%) and $82 / 107$ PBO $\rightarrow$ OL TCZ (77\%) patients completed treatment up to week 96 . Continued decline in mRSS was observed in the OL period for PBO $\rightarrow \mathrm{OL} \mathrm{TCZ}$ and $\mathrm{TCZ} \rightarrow \mathrm{OL} \mathrm{TCZ}$ patients (Table). Change in ppFVC for patients who switched from $\mathrm{PBO}$ to TCZ (PBO $\rightarrow \mathrm{OL} \mathrm{TCZ)} \mathrm{was} \mathrm{comparable} \mathrm{between} \mathrm{weeks} 48$ and 96 (OL period) to the change in patients who received TCZ from BL to week 48 in the DB period (Table). Rates $(95 \% \mathrm{Cl})$ of serious adverse events from weeks 48 to 96 were $15.8(8.6,26.5)$ per 100 PY for TCZ $\rightarrow$ OL TCZ patients, $14.8(7.9,25.3)$ per $100 \mathrm{PY}$ for PBO $\rightarrow$ OL TCZ patients, and $15.4(11.0,20.9)$ for all TCZ exposure over 96 weeks $(n=193)$. Rates $(95 \% \mathrm{Cl})$ of serious infections were $2.3(0.3,8.1)$ per $100 \mathrm{PY}$ for $\mathrm{TCZ} \rightarrow \mathrm{OL} \mathrm{TCZ}$ patients, $3.4(0.7,10.0)$ per $100 \mathrm{PY}$ for $\mathrm{PBO} \rightarrow \mathrm{OL}$ TCZ patients, and $3.0(1.3,5.9)$ for all TCZ exposure over 96 weeks. One death occurred during the $\mathrm{OL}$ period in each arm.

Conclusion: Although OL data have to be interpreted with caution, results from OL TCZ treatment show numeric improvements in mRSS and FVC preservation similar to those of the DB period, with a beneficial effect on trajectory of FVC decline in patients who switched from PBO to TCZ. Long-term safety results were consistent with the known safety profile of TCZ, and no new or unexpected events were observed.

\section{References:}

[1] Khanna D et al. Lancet 2016;387:2630-40.

[2] Khanna D et al. Ann Rheum Dis. 2018;77:212-20.

[3] Khanna D et al. Arthritis Rheumatol 2018:70(suppl 10):abst 898

Disclosure of Interests: Dinesh Khanna Shareholder of: Eicos, Grant/research support from: NIH NIAID, NIH NIAMS, Consultant of: Acceleron, Actelion, Bayer, BMS, Boehringer-Ingelheim, Corbus, Galapagos, Genentech/Roche, GSK, Mitsubishi Tanabi, Sanofi-Aventis/Genzyme, UCB Pharma, Celia J. F. Lin Employee of: Genentech, Helen Spotswood Shareholder of: Roche Products Ltd, Employee of: Roche Products Ltd, Jeff Siegel Employee of: Genentech, Daniel Furst Grant/research support from: AbbVie, Actelion, Amgen, BMS Corbus Pharmaceuticals, the National Institutes of Health, Novartis, Pfizer and Roche/Genentech, Consultant of: AbbVie, Actelion, Amgen, BMS, Cytori Therapeutics, Corbus Pharmaceuticals, the National Institutes of Health, Novartis, Pfizer, and Roche/Genentech, Speakers bureau: CMC Connect (McCann Health Company), Christopher Denton Grant/research support from: GlaxoSmithKline, CSL Behring, and Inventiva, Consultant of: Medscape, Roche-Genentech, Actelion, GlaxoSmithKline, Sanofi Aventis, Inventiva, CSL Behring, Boehringer Ingelheim, Corbus Pharmaceuticals, Acceleron, Curzion and Bayer

DOI: 10.1136/annrheumdis-2020-eular.1535

\section{THU0329 SAFETY, TARGET ENGAGEMENT, AND INITIAL EFFICACY OF AVID200, A FIRST-IN-CLASS POTENT AND ISOFORM-SELECTIVE INHIBITOR OF TGF-BETA 1 AND 3, IN PATIENTS WITH DIFFUSE CUTANEOUS SYSTEMIC SCLEROSIS (DCSSC): A PHASE 1 DOSE ESCALATION STUDY}

R. Lafyatis ${ }^{1}$, R. Spiera ${ }^{2}$, R. Domsic ${ }^{1}$, A. Papazoglou ${ }^{1}$, C. Ligon $^{3}$, C. M. Zinger Morse $^{1}$, J. F. Denis ${ }^{4}$, M. Davis ${ }^{5}$, T. Gruosso ${ }^{4}$, G. Tremblay ${ }^{4}$, M. O'connor Mccourt $^{4}$, S. Sinclair ${ }^{5}$, J. Delara ${ }^{5}$, K. Alvarado ${ }^{5}$, D. Wood ${ }^{5}$, P. Nadler ${ }^{5}$, E. Volkmann ${ }^{6} .{ }^{1}$ University of Pittsburgh, Pittsburgh, United States of America; ${ }^{2}$ Hospital for Special Surgery, New York City, United States of America; ${ }^{3}$ University of Pennsylvania, Philadelphia, United States of America; ${ }^{4}$ Forbius, Montréal, Canada; ${ }^{5}$ Forbius, Austin, United States of America; ${ }^{6}$ UCLA, Los Angeles, United States of America

Background: AVID200 is a novel, potent TGF-beta receptor ectodomain-based trap designed to selectively neutralize TGF-beta 1 and 3 . These two isoforms have been implicated as central mediators of the pathogenesis of systemic sclerosis (SSc). AVID200 avoids inhibition of TGF-beta 2, the isoform that supports normal cardiac function and hematopoiesis.

Objectives: This first-in-human study (AVID200-01; NCT03831438) is a Phase 1 , open label, multicenter, cohort dose-escalation trial designed to evaluate safety, tolerability, pharmacokinetic (PK) profile, pharmacodynamic (PD) effects, target engagement, and preliminary efficacy in patients with diffuse cutaneous $\mathrm{SSc}(\mathrm{dcSSc})$

Methods: Eligible patients must have dcSSc of $<5$ years (y) duration and a modified Rodnan Skin Score (MRSS) $\geq 15$. AVID200 at dose levels of $1,3,9$, or $15 \mathrm{mg} / \mathrm{kg}$ IV is administered every 2 weeks (Q2W) for 6 weeks ( 3 doses). Patients tolerating dosing and who have not experienced disease worsening during the initial Treatment Period may receive up to 6 additional doses Q2W (Extension Period). The ability of AVID200 to selectively sequester its target is assessed in plasma by TGF-beta quantification per ELISA and a cell-based functional readout. Expression of biomarkers of TGF-beta inhibition and genes correlating with MRSS are assessed.

Table. Change in Efficacy From Baseline

\begin{tabular}{|c|c|c|c|c|c|c|}
\hline & \multicolumn{2}{|c|}{ Baseline to Week 48} & \multicolumn{2}{|c|}{ Baseline to Week 96} & \multicolumn{2}{|c|}{ Week 48 to Week 96} \\
\hline & PBO & TCZ & $\mathrm{PBO} \rightarrow \mathrm{OLTCZ}$ & $\mathrm{TCZ} \rightarrow \mathrm{OL} \mathrm{TCZ}$ & $\mathrm{PBO} \rightarrow \mathrm{OL} \mathrm{TCZ}$ & $\mathrm{TCZ} \rightarrow \mathrm{OL} \mathrm{TCZ}$ \\
\hline mRSS, mean $(95 \% \mathrm{Cl})^{\mathrm{a}}$ & $\begin{array}{c}-5.3(-6.9,-3.7) \\
n=92\end{array}$ & $\begin{array}{c}-6.7(-8.0,-5.4) \\
n=97\end{array}$ & $\begin{array}{c}-8.4(-10.0,-6.8) \\
n=83\end{array}$ & $\begin{array}{c}-9.6(-10.9,-8.4) \\
n=85\end{array}$ & $\begin{array}{c}-2.5(-3.3,-1.6) \\
n=82\end{array}$ & $\begin{array}{c}-2.3(-3.2,-1.5) \\
n=85\end{array}$ \\
\hline ppFVC, mean $(95 \% \mathrm{Cl})$ [median] & $\begin{array}{c}-4.1(-5.8,-2.4)[-3.9] \\
n=92\end{array}$ & $\begin{array}{c}-0.2(-1.6,1.2)[-0.7] \\
\mathrm{n}=94\end{array}$ & $\begin{array}{c}-3.3(-5.1,-1.5)[-3.1] \\
n=79\end{array}$ & $\begin{array}{c}-0.5(-2.4,1.3)[-1.4] \\
n=84\end{array}$ & $\begin{array}{c}0.6(-0.7,1.9)[0.3] \\
\mathrm{n}=78\end{array}$ & $\begin{array}{c}-0.3(-1.7,1.1)[0.0] \\
n=82\end{array}$ \\
\hline Decline in ppFVC $\geq 10 \%, n / N(\%)^{a}$ & $\begin{array}{l}15 / 91 \\
(16.5)\end{array}$ & $\begin{array}{l}5 / 93 \\
(5.4)\end{array}$ & $14 / 79(17.7)$ & $11 / 84(13.1)$ & NA & NA \\
\hline Improvement in ppFVC, $\mathrm{n} / \mathrm{N}(\%)^{\mathrm{a}}$ & $\begin{array}{l}26 / 91 \\
(28.6)\end{array}$ & $\begin{array}{l}43 / 93 \\
(46.2)\end{array}$ & $\begin{array}{l}22 / 79 \\
(27.8)\end{array}$ & $\begin{array}{l}35 / 84 \\
(41.7)\end{array}$ & NA & NA \\
\hline
\end{tabular}

${ }^{a}$ Observed data. NA, not assessed. 
Results: The first 2 dose cohorts have completed treatment: male/female 3 each, median age 61y (range 45-70), median MRSS at baseline 31 (range 23-39). Recruitment into cohort 3 is complete. AVID200 was well tolerated with no dose limiting toxicities or serious adverse events (SAEs). AEs, all considered possibly related, included single cases of Grade 1 dizziness and CPK elevation, and Grade 2 anemia. All patients demonstrated a decline in MRSS at 6 weeks by 3,4 , and 9 points in Cohort 1 , and 2, 8, and 9 points in Cohort 2. Four of 6 patients demonstrated continued decrease in MRSS 12 weeks after the last dose, with all patients showing a decline in MRSS relative to baseline at this timepoint by 7,6 , and 7 points in Cohort 1 and 4,8 , and 13 points in Cohort 2. AVID200 in plasma engaged endogenous activated TGF-beta and potently neutralized signaling from exogenous TGF-beta 1 and 3 , but not TGF-beta 2, across the treatment period. PD effects in skin biopsies, including expression of markers of SSc activity, TGF-beta activity, and myofibroblast-associated genes were assessed. Five of 6 patients showed decreased expression of PD biomarker genes, THBS1 and MS4A4A, comparing end of treatment biopsies to baseline, and all patients showed a decline in SERPINE1 expression, a marker gene for TGF-beta activity. Clustering of RNA-seq expression data showed close coregulation of COMP, THBS1, SERPINE1, LOXL, COL10A1, COL11A1, COL12A1, CTGF, and CDH11, suggesting that blocking TGF-beta inhibits this group of profibrotic genes. Single-cell sequencing data show that expression of these genes is upregulated by subsets of SSc fibroblasts.

Conclusion: AVID200 at doses of 1 and $3 \mathrm{mg} / \mathrm{kg}$ was well-tolerated in this first study in dcSSc patients. Evidence of anti-fibrotic effects as indicated by rapid, persistent and clinically meaningful declines in MRSS was observed in all patients, as well as AVID200 target engagement and modulation. Recruitment into additional dose and extension cohorts is ongoing. Together, these clinical data support selective TGF-beta 1 and 3 inhibition by AVID200 as a promising therapeutic approach for dcSSc.

Disclosure of Interests: Robert Lafyatis Grant/research support from: Forbius, Consultant of: Certa Therapeutics, Forbius, FBM Therapeutics, Robert Spiera Grant/research support from: Roche-Genetech, GSK, Boehringer Ingelheim, Chemocentryx, Corbus, Forbius, Sanofi, Inflarx, Consultant of: Roche-Genetech, GSK, CSL Behring, Sanofi, Janssen, Chemocentryx, Forbius, Mistubishi Tanabe, Robyn Domsic Consultant of: Forbius, Anna Papazoglou: None declared, Colin Ligon Grant/research support from: Forbius, Christina Mae Zinger Morse: None declared, Jean-François Denis Employee of: Forbius, Margaret Davis Employee of: Forbius, Tina Gruosso Employee of: Forbius, Gilles Tremblay Employee of: Forbius, Maureen O'Connor McCourt Employee of: Forbius, Sandra Sinclair Employee of: Forbius, Jonathan Delara Employee of: Forbius, Krista Alvarado Employee of: Forbius, Debra Wood Consultant of: Forbius, Symphogen, Paul Nadler Consultant of: Forbius, Symphogen, Karyopharm, Elizabeth Volkmann Grant/research support from: Forbius, Corbus Pharmaceuticals, Consultant of: Boehringer Ingelheim, Forbius, Speakers bureau: Boehringer Ingelheim

DOI: 10.1136/annrheumdis-2020-eular.1753

\section{THU0330 SYSTEMIC SCLEROSIS-ASSOCIATED ILD (SSC-ILD) AND DIFFERING EXTENTS OF SKIN FIBROSIS: FURTHER ANALYSES OF THE SENSCIS TRIAL}

Y. Allanore ${ }^{1}$, V. Steen ${ }^{2}$, M. Kuwana ${ }^{3}$, C. Denton ${ }^{4}$, M. Matucci-Cerinic ${ }^{5}$ E. Volkmann ${ }^{6}$, D. Khanna ${ }^{7}$, D. Wachtlin ${ }^{8}$, M. Gahlemann ${ }^{9}$, M. Quaresma ${ }^{10}$, M. Alves ${ }^{10}$, O. Distler ${ }^{11}$ on behalf of the SENSCIS Trial Investigators. ${ }^{1}$ Department of Rheumatology A, Descartes University, APHP, Cochin Hospital, Paris, France; ${ }^{2}$ Division of Rheumatology, Georgetown University, Washington DC, United States of America; ${ }^{3}$ Department of Allergy and Rheumatology, Nippon Medical School Graduate School of Medicine, Tokyo, Japan; ${ }^{4}$ University College London Division of Medicine, Centre for Rheumatology and Connective Tissue Diseases, London, United Kingdom; ${ }^{5}$ University of Florence, Department of Medicine, Florence, Italy; ${ }^{6}$ Department of Medicine, Division of Rheumatology, University of California, David Geffen School of Medicine, Los Angeles, California, United States of America; ${ }^{7}$ Department of Medicine, University of Michigan, Ann Arbor, MI, United States of America; ${ }^{8}$ Boehringer Ingelheim Pharma GmbH \& Co. KG, Ingelheim, Germany; ${ }^{9}$ Boehringer Ingelheim (Schweiz) $\mathrm{GmbH}$, Basel, Switzerland; ${ }^{10}$ Boehringer Ingelheim International $\mathrm{GmbH}$, Ingelheim, Germany; ${ }^{11}$ Department of Rheumatology, University Hospital Zurich, Zurich, Switzerland

Background: In the SENSCIS trial, nintedanib reduced the progression of SScILD compared with placebo, as shown by a significantly lower rate of decline in forced vital capacity (FVC) over 52 weeks. There was no significant difference between treatment groups in change in modified Rodnan skin score (mRSS) at week 52. An mRSS of 18-25 has been proposed as an upper cut-off to enrich a cohort for skin-progressive patients. Progression of skin fibrosis has been associated with later progression of ILD.

Objectives: To assess the effects of nintedanib on the rate of FVC decline and change in mRSS in the SENSCIS trial in subgroups by $\mathrm{mRSS}<18$ and $\geq 18$ at baseline.

Methods: Patients with SSc-ILD with onset of first non-Raynaud symptom $<7$ years before screening and $\geq 10 \%$ fibrosis of the lungs on a high-resolution computed tomography scan were randomised to receive nintedanib or placebo. We analysed the rate of decline in FVC (ml/year) over 52 weeks and the change from baseline in mRSS at week 52 in subgroups by mRS $(<18 ; \geq 18)$ at baseline.

Results: In the nintedanib and placebo groups, respectively, 219/288 (76.0\%) and $226 / 288(78.5 \%)$ patients had mRSS $<18$ at baseline. Compared with those with $\mathrm{mRSS}<18$, patients with $\mathrm{mRSS} \geq 18$ had a lower mean FVC \% predicted $(68.3 \%$ vs $73.7 \%)$ and greater proportions were taking mycophenolate at baseline $(58.1 \%$ vs $45.6 \%)$, were anti-topoisomerase I antibody positive $(67.4 \%$ vs $58.7 \%$ ) and had diffuse cutaneous SSc (100\% vs $37.8 \%)$. The mean (SE) annual rate of decline in FVC in the placebo group was numerically greater in patients who had $\mathrm{mRSS} \geq 18$ than $\mathrm{mRSS}<18$ at baseline $(-131.7$ [29.2] $\mathrm{mL} /$ year vs -81.4 [15.4] $\mathrm{mL} /$ year). The effect of nintedanib vs placebo on reducing the annual rate of decline in FVC was numerically more pronounced in patients with $\mathrm{mRSS} \geq 18$ (difference: $88.7 \mathrm{~mL} /$ year [95\% Cl 7.7, 169.8]) than mRSS $<18$ (difference: $26.4 \mathrm{~mL} /$ year $(95 \% \mathrm{Cl}-16.8,69.6)$ at baseline, but statistical testing did not indicate heterogeneity in the treatment effect of nintedanib between subgroups ( $\mathrm{p}=0.18$ for treatment-by-time-by-subgroup interaction) (Figure). In the nintedanib and placebo groups, respectively, changes in mRSS at week 52 were $-2.2(0.3)$ and $-2.1(0.3)$ (difference $-0.1[95 \% \mathrm{Cl}-1.0,0.7]$ ) in patients with mRSS <18 at baseline and $-2.1(0.7)$ and $-1.6(0.7)$ (difference $-0.6[95 \% \mathrm{Cl}-2.1,1.0]$ ) in patients with $\mathrm{mRSS} \geq 18$ at baseline $(p=0.62$ for treatment-by-visit-by-subgroup interaction).

Conclusion: In the placebo group of the SENSCIS trial, the rate of decline in FVC over 52 weeks was numerically greater in patients with $\mathrm{mRSS} \geq 18$ than $<18$ at baseline, while reductions in mRSS were similar. A lower rate of FVC decline was observed in patients treated with nintedanib than placebo both in patients with $\mathrm{mRSS} \geq 18$ and $<18$ at baseline.

Figure. Rate of decline in FVC over 52 weeks in subgroups by mRSS $<18$ and $\geq 18$ at baseline in the SENSCIS tria

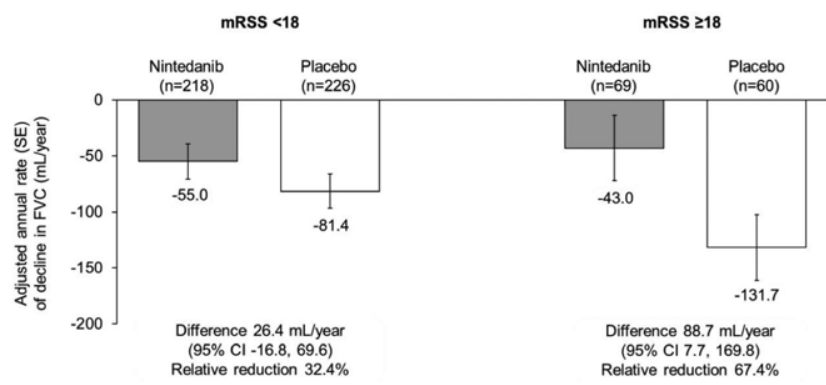

Treatment-by-time-by-subgroup interaction $p=0.18$

Acknowledgments: The SENSCIS trial was funded by Boehringer Ingelheim Disclosure of Interests: Yannick Allanore Grant/research support from: Yannick Allanore has received grants from Inventiva, Roche and Sanofi, Consultant of: Yannick Allanore has received fees from Actelion, Bayer, Boehringer Ingelheim, Bristol-Myers Squibb, Curzion, Inventiva, Roche, Sanofi, Viginia Steen Grant/research support from: The associated affiliation has received grants/research from Boehringer Ingelheim, Corbus Pharmaceuticals, CSL Behring, Eicos, Galapagos, Immune Tolerance Network, Reata, Consultant of: Virginia Steen has acted as a consultant for Boehringer Ingelheim, Corbus, CSL Behring, Eicos, Forbius, Masataka Kuwana Grant/research support from: Acetelion, Consultant of: Acetelion, Bayer, Chugai, Corbus Pharmaceuticals CSL Behring and Reata Pharmaceuticals. He was a member of the SENSCIS trial Steering Committee (Boehringer Ingelheim), Christopher Denton Grant/research support from: GlaxoSmithKline, CSL Behring, and Inventiva, Consultant of: Medscape, Roche-Genentech, Actelion, GlaxoSmithKline, Sanofi Aventis, Inventiva, CSL Behring, Boehringer Ingelheim, Corbus Pharmaceuticals, Acceleron, Curzion and Bayer, Marco Matucci-Cerinic Grant research support from: Actelion, MSD, Bristol-Myers Squibb, Speakers bureau: 